\title{
The Response of Spring Wheat Cultivars to Arbuscular Mycorrhizal Colonization under Salinity Stresses
}

\author{
Daishu Yi ${ }^{1}$, Timothy Schwinghamer ${ }^{1}$, Yolande Dalpé ${ }^{2}$ Jaswinder $\operatorname{Singh}^{1} \&$ Shahrokh Khanizadeh $^{2}$ \\ ${ }^{1}$ Department of Plant Science, McGill University, 21111 Lakeshore Road, Sainte-Anne-De-Bellevue, Quebec, \\ Canada \\ ${ }^{2}$ Ottawa Research and Development Centre, Agriculture and Agri-Food Canada, K.W. Neatby Building, 960 \\ Carling Avenue, Ottawa, Ontario, Canada \\ Correspondence: Shahrokh Khanizadeh, Ottawa Research and Development Centre, Agriculture and Agri-Food \\ Canada, K.W. Neatby Building, 960 Carling Avenue, Ottawa, Ontario, Canada. E-mail: \\ Shahrokh.khanizadeh@agr.gc.ca, http://khanizadeh.info
}

Received: November 16, 2016 Accepted: February 17, 2017 Online Published: March 1, 2017

doi:10.5539/sar.v6n2p58

URL: https://doi.org/10.5539/sar.v6n2p58

\begin{abstract}
Wheat is an important crop, playing inevitable roles in human life, ranging from major food resource to raw material for biofuel. However, due to the dramatically reduced available arable areas and increasingly severe abiotic and biotic stresses, wheat production nowadays faces extreme challenges.. Many approaches have been explored to increase wheat yield including development of new cultivars. One of the most promising approaches is the application of the naturally existent arbuscular mycorrhiza (AM), a mutualistic symbiosis originated over 400 million years ago. AM have long been known to form mutualistic symbiosis with various plants to enhance yield production and to improve stress tolerance, especially drought and salinity. But the benefits vary among AM strains and plant species. Therefore, the objective of the study was to investigate the influence of four AM strains colonized on four selected spring wheat varieties under three salt concentrations $(0,50,100 \mathrm{mmol} / \mathrm{L})$. The results demonstrated that wheat inoculated with arbuscular mycorrhizal strains Funneliformis mosseae and Rhizoglomusirregulare mitigated yield losses caused by increased salinity stresses as well as strengthened root growth in comparison with non-inoculated plant controls. Salinity stress, however, had non-significant negative effects on most variables, except for grain yield, root surface area and root dry weight, in which a significant decrease was observed in root surface area and root dry weight with the increasing of saline concentration.
\end{abstract}

Keywords: arbuscular mycorrhizae, root morphology, salinity stress, wheat (spring)

\section{Introduction}

Wheat (Triticum aestivum L.) ranks among the top cereal crops and is grown in diverse agricultural ecosystems around the world. In 2013, with a global production of over 0.71 billion t, Wheat occupied the third position of most produced crop over the world, after 0.74 billion $t$ of rice and over 1 billion t of maize (Food and Agriculture Organization of the United Nations, 2013). Wheat is planted on more than $17 \%$ of the global crop acreage and it successfully feeds over two-fifths of the population worldwide (Gupta et al., 2008). Today, however, numerous severe stresses, both biotic and abiotic, negatively impede the global wheat production: one of the most severe concerns is soil salinization (Günal et al., 2015). Many approaches have been applied to alleviate yield loss caused by soil salinization, including the exploration of novel stress-tolerant cultivars through modern breeding methods (Mozafar and Goodin, 1986), the optimization of cultivation systems to reduce the negative effects of salinization (Sun et al., 2010), as well as the application of naturally existing beneficial symbioses (Beltrano and Ronco, 2008). One of the most promising approaches is the exploration and use of arbuscular mycorrhizae, a mutualistic symbiosis that could protect plants from salinity damages.

With a history of more than 400 million years, arbuscular mycorrhizae are considered to be one of the world's oldest and most prevalent symbioses formed between plants and fungi (Parniske, 2008; Pirozynski and Malloch, 1975; Remy et al., 1994). Previous studies have reported that more than $85 \%$ of the documented plant species are putative hosts of arbuscular mycorrhizal fungi (AMF) and that those species benefit from the symbiosis in various ways, including increased absorption of water and mineral nutrients (especially phosphorus, the crucial mineral for plant growth and development) and improved biotic and abiotic stress tolerance through multiple 
complex mechanisms (Daei et al., 2009; Harley and Smith, 1997; Marschner and Dell, 1994; Pozo et al., 2010; Wang and Qiu, 2006). An increase in salinity tolerance was observed in numerous mycorrhizal colonized plants, including crops such as barley and wheat (Rad et al., 2009; Talaat and Shawky, 2014). Nevertheless, such benefits vary depending on the AMF strains selected and the host plant species involved (Gong et al., 2013; Zou and $\mathrm{Wu}, 2011)$. Therefore, the objective of this project was to evaluate the response of four selected spring wheat genotypes to inoculation with four arbuscular mycorrhizal strains under three salt concentrations.

\section{Materials and Methods}

\subsection{Experimental Materials}

\subsubsection{Wheat Cultivars}

Four spring wheat cultivars, namely FL62R1, Scotia, Snowbird, and 13NQW1265, were analyzed in the current study (Table 1). In addition to plant biomass and root morphology, the relationship between grain colour and antioxidant components and their responses to wheat mycorrhization were also of great interest. Therefore, the four spring wheat cultivars chosen for our study were mainly because of their respective grain colours (red, white or purple). On one hand, changes in plant biomass and root morphology were measured and analyzed. On the other hand, the harvested grains were further processed for the analysis of grain antioxidant components to determine differences in the antioxidant capacity of coloured wheat with and without arbuscular mycorrhizal inoculation.

Table 1. Wheat cultivars, arbuscular mycorrhizal (AM) strains, and salinity treatments of the experimental design

\begin{tabular}{|c|c|c|}
\hline \multicolumn{3}{|c|}{ Spring wheat cultivars } \\
\hline Wheat cultivar & Grain colour & Seeds per pot \\
\hline FL62R1 & Red & 5 \\
\hline Scotia & Red & 5 \\
\hline Snowbird & White & 5 \\
\hline \multicolumn{3}{|c|}{ AM strains } \\
\hline AM strain ${ }^{\text {a) }}$ & $\mathrm{DAOM}^{\mathrm{b})}$ & Number of propagules per pot \\
\hline Funneliformis + mosseae & 198274 & 50 \\
\hline Funneliformis caledonius & 242686 & 50 \\
\hline Rhizoglomus irregulare & 240442 & 50 \\
\hline Myke & 197198 & 50 \\
\hline \multicolumn{3}{|c|}{ Salinity treatments } \\
\hline Saline solution $\left(\mathrm{mmolL}^{-1}\right)$ & grams of $\mathrm{NaCl}\left(\mathrm{L}^{-1}\right)$ & Volume of saline solution per pot (L) \\
\hline 0 & 0 & 0.1 \\
\hline 50 & 2.925 & 0.1 \\
\hline 100 & 5.85 & 0.1 \\
\hline
\end{tabular}

a) The arbuscular mycorrhizal strains Rhizoglomus irregulare (DAOM 240442) and Myke (DAOM 197198) originate from the same mycorrhizal species but are different strains.

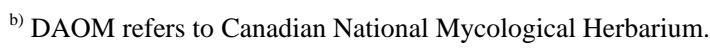

\section{--Arbuscular mycorrhizal strains (AMF strains)}

Four AMF strains, namely Funneliformis mosseae (DAOM 198274), F. caledonium (DAOM 242686), and two Rhizoglomus irregulare strains (DAOM 240442) and the commercial product Myke (DAOM 197198). The AMF strains were obtained from the Glomeromycota in vitro and in vivo Collection, Ottawa Research and Development Centre, Agriculture and Agri-Food Canada.

\section{--Salinity treatments}

Saline solutions were made with sodium chloride $(\mathrm{NaCl})$, and three salinity levels $\left(0,50\right.$, or $\left.100 \mathrm{mmolL}^{-1}\right)$ were used.

\subsection{Methods}

A greenhouse experiment was conducted under controlled condition with a $16-\mathrm{h}$ photoperiod and a $22^{\circ} \mathrm{C} / 20^{\circ} \mathrm{C}$ day/night temperature regime. For each of the four wheat cultivars, five seeds inoculated with one AMF strain at 
a rate of 50 spores were planted in each $15.25 \mathrm{~cm}$ (6-inch) pot, with equal distances between the seeds. Non-inoculated seeds were also planted for each cultivar as controls. Each inoculant was provided in the form of a specific matrix containing relevant AMF spores. The non-mycorrhizal controls were treated with mycorrhizal-free soil instead of mycorrhizal-spore-containing matrix. A total of 360 pots were used, with 60 pots per replicate and 6 replicates, arranged according to a randomized complete block design. The AGRO MIX G10 (AF) soil was used as Substrate matrix to guarantee no extra mycorrhizal fungi in the soil. Constant irrigation was provided throughout the growth period but was stopped on the days when the saline treatments were applied. The plants were fertilized with $100 \mathrm{ml} 20-20-20 \mathrm{~N}-\mathrm{K}-\mathrm{P}\left(1 \mathrm{~g} \mathrm{~kg}^{-1}\right)$ per pot every two weeks.

Salinity treatment with $100 \mathrm{ml}$ of $\mathrm{NaCl}$ solution $\left(0,50\right.$, or $\left.100 \mathrm{mmolL}^{-1}\right)$ per pot was initialled on the fifth week of growth and continued at 3-d intervals for six weeks until harvest. Data on grain yield, root length, root surface area, total root volume, root fresh weight, and root dry weight were collected and measured. Root morphological parameters were collected with WinRHIZO Pro Regent Instruments software and root dry weight was then measured after the roots had been dried in an oven at $60^{\circ} \mathrm{C}$ for $3 \mathrm{~d}$. The data were analyzed using PROC GLIMMIX (Generalized Linear Mixed Models) of the SAS software package.

\section{Results}

\subsection{Plant Biomass}

Grain yield, root fresh weight and root dry weight were measured and analyzed as indicators of plant biomass.

\section{--Grain yield}

Grain yield was significantly affected by the interaction between mycorrhizal strains and salinity treatments with a $P$-value of 0.0121 (Table 1). Specifically, salinity levels had a significantly negative effect on yield production in the non-mycorrhizal controls $(P=0.0205)$ and in the wheat cultivars inoculated with $F$. caledonius $(P=$ 0.0027), which exhibited a significant yield decrease when treated with the $\mathrm{NaCl}$ solution at $100 \mathrm{mmolL}^{-1}$ in comparison with the non-salt-treated controls. There were, however, no significant changes in grain yield between the salt and non-salt treatments when the wheat had been inoculated with the other AMF strains, indicating that colonization with F. mosseae, R. irregulare, and Myke benefited the host wheat by efficiently mitigating saline-induced yield decreases.

Table 2. Effect of interaction between mycorrhizal strains and salinity levels on grain yield, sliced by mycorrhizal strain $(\alpha=0.05)$

\begin{tabular}{cccc|}
\hline AM strains & Salinity levels $\left(\mathbf{m m o l}^{-\mathbf{1}}\right)$ & $\boldsymbol{P}$-value & Grain yield (estimates) $^{\text {a) }}$ \\
\hline Funneliformis & 0 & $P=0.5024$ & $0.6534 a^{\mathrm{b})}$ \\
mosseae & 50 & & $0.7682 a$ \\
& 100 & $P=0.0027$ & $0.6935 a$ \\
Funneliformis & 0 & & $0.8746 a$ \\
caledonius & 50 & $P=0.3737$ & $0.8243 a$ \\
& 100 & & $0.5577 b$ \\
Rhizoglomus & 0 & $0.7011 a$ \\
irregulare & 50 & & $0.8326 a$ \\
& 100 & & $0.7961 a$ \\
Myke & 0 & & $0.7156 a$ \\
& 50 & $0.5693 a$ \\
Control & 100 & $0.6765 a$ \\
& 0 & & $0.8390 a$ \\
& 50 & & $0.6743 a b$ \\
Mycorrhizal strains * salinity levels ${ }^{\mathrm{c})}$ & & $0.5667 b$ \\
id presented as estimates, because there was difficulty with the transformation back into means. \\
followed by the same letters are not significantly different with $95 \%$ confidence limits. \\
y-interaction between mycorrhizal strains and salinity levels was found.
\end{tabular}

\section{--Root fresh weight}

Root fresh weight was significantly influenced by the wheat-mycorrhiza interaction, with a $P$-value of 0.0137 (Table 3). Salt treatment, however, had no significant effect on root fresh weight $(P=0.0548)$. Specifically, the 
wheat cultivars Snowbird and 13NQW1265 responded positively to inoculation with $R$. irregulare, resulting in significantly heavier root fresh weights in comparison with the non-inoculated controls, as shown in Table 3. Nevertheless, inoculation of either Snowbird or 13NQW1265 with the other AMF, namely, F. mosseae, F. caledonius, and the commercial strain Myke, generally had no significant effects on root fresh weight, presenting as no significant differences in root fresh weight between the inoculated plants and the non-inoculated controls. The only exception was the F. mosseae-inoculated Snowbird, which responded positively to that AMF and produced a significantly heavier root fresh weight than non-inoculated Snowbird did. FL62R1 and Scotia did not exhibit any significant change in root fresh weight in response to plant mycorrhization. Furthermore, it was noticed that even though the non-commercial mycorrhizal strain $R$. irregulare and the commercial strain Mykebelonged to the same AMF species, the performance of Mykewas apparently worse than that of $R$. irregulare, particularly in the cultivars FL62R1 and Scotia. Root fresh weight was significantly heavier in the $R$. irregulare -inoculated FL62R1 than in the Myke-inoculated FL62R1. Similarly, heavier root fresh weight was observed in the Scotia wheat inoculated with $R$. irregulare than in the same cultivar inoculated with Myke. In addition, the wheat cultivar FL62R1 (whether inoculated or non-inoculated) generally had higher levels of root fresh weight, whereas Snowbird (whether inoculated or non-inoculated) had the lower root fresh weight. These findings show that the wheat cultivar FL62R1 was the best option among these four experimental spring wheat genotypes in terms of producing stronger root systems.

Table 3. Effect of interaction between mycorrhizal strains and wheat cultivars on root fresh weight, sliced by wheat cultivar $(\alpha=0.05)$

\begin{tabular}{|c|c|c|c|}
\hline Wheat cultivars & Mycorrhizal strains & $P$-value & Root fresh weight (means) $)^{\text {a) }}$ \\
\hline \multirow[t]{5}{*}{ FL62R1 } & Funneliformismosseae & $P=0.0425$ & $2.4593 a b^{\mathrm{b})}$ \\
\hline & Funneliformiscaledonius & & $2.6365 a b$ \\
\hline & Rhizoglomus irregulare & & $3.0955 a$ \\
\hline & Myke & & $2.1972 b$ \\
\hline & Control & & $2.6191 a b$ \\
\hline \multirow[t]{5}{*}{ Scotia } & Funneliformis mosseae & $P=0.0179$ & $2.1776 a b$ \\
\hline & Funneliformis caledonius & & $2.1834 a b$ \\
\hline & Rhizoglomus irregulare & & $2.2746 a$ \\
\hline & Myke & & $1.7020 b$ \\
\hline & Control & & $2.1886 a b$ \\
\hline \multirow[t]{5}{*}{ Snowbird } & Funneliformis mosseae & $P=0.0016$ & $1.8465 a$ \\
\hline & Funneliformis caledonius & & $1.3465 a b$ \\
\hline & Rhizoglomus irregulare & & $1.8073 a$ \\
\hline & Myke & & $1.6429 a b$ \\
\hline & Control & & $1.2751 b$ \\
\hline \multirow[t]{5}{*}{ 13NQW1265 } & Funneliformis mosseae & $P=0.0108$ & $2.2588 a b$ \\
\hline & Funneliformis caledonius & & $2.0449 a b$ \\
\hline & Rhizoglomus iirregulare & & $2.4982 a$ \\
\hline & Myke & & $1.9780 a b$ \\
\hline & Control & & $1.9036 b$ \\
\hline \multicolumn{2}{|c|}{ Mycorrhizal strains $*$ wheat cultivars ${ }^{\mathrm{c}}$} & & $P=0.0137$ \\
\hline
\end{tabular}

\section{--Root dry weight}

Root dry weight was significantly affected by AMF strain $(P<0.0001)$, and salinity treatment $(P=0.0234)$ independently (Tables 4 and 5). A significant difference was observed between cultivars $(P<0.0001)$. In terms of the evaluation of wheat cultivars, FL62R1 had the heaviest root dry weight, whether inoculated with mycorrhizal fungi or not. The cultivar Snowbird had the lowest root dry weight, whereas Scotia and 13NQW1265 had relatively moderate root dry weights, which were lower than that of wheat FL62R1 but higher than that of Snowbird. Multiple comparisons between the wheat plants colonized by the mycorrhizal strains $F$. mosseae, F. caledonius, and $R$. irregulare and the non-mycorrhizal controls indicate that mycorrhizal inoculation significantly improved root dry weight. The only exception was inoculation with the commercial AMF strain 
Myke, given that Myke colonization had no significant effects on the wheat cultivars in comparison with the non-inoculated controls.

Table 4. Back-transformedmeans ${ }^{\text {a) }}$ for root morphology and root dry weight with Bonferroni grouping $(\alpha=0.05)$

\begin{tabular}{|c|c|c|c|c|}
\hline & $\begin{array}{c}\text { Root } \\
\text { length } \\
(\mathbf{m m})\end{array}$ & $\begin{array}{c}\text { Surface area } \\
(\mathbf{m m} * \mathbf{m m})\end{array}$ & $\begin{array}{c}\text { Root volume } \\
(\mathbf{m m} * \mathbf{m m} * \mathbf{m m})\end{array}$ & $\begin{array}{c}\text { Root dry weight } \\
\text { (grams) }\end{array}$ \\
\hline \multicolumn{5}{|c|}{ Wheat cultivars } \\
\hline FL62R1 & $280.07 a^{\mathrm{c})}$ & $84.7314 a$ & $2.0491 a$ & $0.5401 a$ \\
\hline Scotia & $287.98 a$ & $79.0213 a b$ & $1.725 a b$ & $0.4618 b$ \\
\hline Snowbird & $239.03 b$ & $58.6932 c$ & $1.2598 c$ & $0.3544 c$ \\
\hline 13NQW1265 & $304.79 a$ & $75.2293 b$ & $1.438 b c$ & $0.437 b$ \\
\hline$P$-value & $P<0.0001$ & $P<0.0001$ & $P<0.0001$ & $P<0.0001$ \\
\hline \multicolumn{5}{|c|}{ Mycorrhizal strains ${ }^{d)}$} \\
\hline F.mosseae & $301.60 a$ & $81.2535 a b$ & $1.744 a b$ & $0.4732 a$ \\
\hline F.caledonius & $252.54 b c$ & $64.8801 c d$ & $1.3384 c$ & $0.4556 a$ \\
\hline R.iirregulare & $320.13 a$ & $88.5825 a$ & $1.9599 a$ & $0.5121 a$ \\
\hline Myke & $237.81 c$ & $63.7823 d$ & $1.3682 b c$ & $0.392 b$ \\
\hline Control & $280.57 a b$ & $73.19 b c$ & $1.696 a b c$ & $0.3959 b$ \\
\hline$P$-value & $P<0.0001$ & $P<0.0001$ & $P<0.0001$ & $P<0.0001$ \\
\hline
\end{tabular}

\footnotetext{
a) The four variables were analyzed based on their different distributions, and thus the means here are back-transformed means.

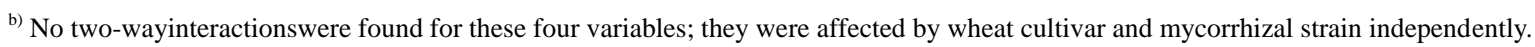

c) Means followed by the same letters are not significantly different with $95 \%$ confidence limits.

${ }^{\text {d) }}$ F. mosseae $=$ Funneliformis mosseae; F. caledonius =Funneliformis caledonius; R. iirregulare=Rhizoglomusirregulare .
}

Table 5. Back-transformedmeans $\mathrm{s}^{\text {a) }}$ for root surface area and root dry weight under salinity effects with Bonferroni grouping $(\alpha=0.05)$

\begin{tabular}{|ccc|}
\hline Salinity levels $\left(\mathbf{m m o l L}^{-\mathbf{1}}\right)$ & Surface area $(\mathbf{m m} * \mathbf{m m})^{\mathbf{b})}$ & Root dry weight (grams) \\
\hline 0 & $76.9581 a^{\mathrm{c})}$ & $0.4615 a$ \\
50 & $74.4342 a b$ & $0.4493 a b$ \\
100 & $69.9915 b$ & $0.4203 b$ \\
$P$-value & $P=0.0200$ & $P=0.0234$ \\
\hline
\end{tabular}

\footnotetext{
a) The two variables were analyzed based on their different distributions, and thus the means here are back-transformed means

b) No two-wayinteractionswere found for these variables, and therefore they were affected by salinity level independently.

c) Means followed by the same letters are not significantly different with $95 \%$ confidence limits.
}

\subsection{Root Morphology}

Total root length, root surface area, and total root volume were measured as representatives of root morphological variables. All the three root architecture parameters depended to the wheat cultivar and the mycorrhizal strain, independently (Table 4). The two-way interaction was not statistically significant at the $P=0.05$ level. Generally, the results indicate that inoculation with $R$. irregulare benefited the host wheat by strengthening root development, which was quantified by larger total root volume, longer root length, and greater root surface area. Root surface area was taken as an example here. A comparison between the $R$. irregulare-inoculated wheat plants and the non-mycorrhizal controls indicates that colonization by $R$. irregulare fungus appeared to positively promote root growth and development, contributing to significantly larger root surface area. From the perspective of wheat cultivar selection, the results demonstrate that the wheat cultivars exhibited different root morphology responses. Generally, cultivar FL62R1 and Scotia had the best performance for all variables, resulting in the longest root length, largest root surface area, and largest root volume, whereas the commonly used cultivar Snowbird had the poorest performance, with the lowest values for all the root morphology variables measured.

\subsection{Salinity Effects}

The results show that the salinity had a non-significant effect on root length, total root volume, root fresh weight. 
In addition to negatively affecting grain yield through an interaction with mycorrhizal strain as discussed above, the salinity treatments also had significantly negative effects on root surface area and root dry weight. Specifically, root surface area and root dry weight decreased significantly under the highest-concentration of salt solution $\left(100 \mathrm{mmolL}^{-1}\right)$ in comparison with the non-salt control in all wheat-mycorrhizal combinations, and the decrease could be well-described by linear regression. These findings suggest that even the highest level of saline stress applied in this study may be far below the salt sensitivity of wheat cultivars, with the result that the effects of salt were non-significant on most of the variables in this study.

\section{Discussion and Conclusion}

\subsection{Plant Biomass and Root Morphology}

Taken together, the above findings demonstrate that the mycorrhizal strains $F$. mosseae and $R$. irregulare improved the performance of the experimental wheat cultivars in terms of both plant biomass (grain yield and root biomass) and root morphology among the four selected AMF strains. Wheat colonized by F. mosseae or $R$. irregulare showed significant advantages in terms of both the mitigation of saline-induced yield loss and the promotion of root development, with heavier root biomass and optimized root architecture in comparison with the non-inoculated controls. However, the performance of mycorrhizal strains F. caledonius and Myke varied among the variables.

With respect to plant biomass, the results illustrate that wheat inoculated with $F$. mosseae and $R$. irregulare experienced lower yield loss under salinity stress and produced heavier root biomass. These effects may be due in part to the integrated effects, which include: increased uptake of phosphorus (which functions as the crucial nutrient and material base for plant development and growth),enhanced water absorption and water-use efficiency (which allow the plant to fight against salinity-induced physiological water shortages),and more efficient photosynthesis (which provides more carbohydrates and improves the transportation rate between the plant and the fungus in the mycorrhizal symbiosis) (Collaet al., 2008; Sheng et al., 2008; Talaat and Shawky, 2013).

It has been widely reported that mycorrhizae help plants to improve their tolerance against salinity stresses through multiple mechanisms, including changes in root morphology and the enhancement of water and nutrient uptake. The comprehensive effects therefore improve plant vigour and provide hosts with heavier root biomass in comparison with non-mycorrhizal controls under saline conditions (Evelin et al., 2009; Porcel et al., 2012). In consequence, evaluations on root biomass and yield production are insufficient to provide enough information for a full understanding of the influence of plant mycorrhization. As previously reported by Iman et al., (2006), root morphology may change without significant differences in root biomass. Therefore, in addition to root biomass, root morphological parameters must also be evaluated, as was done in this study.

Optimized root architecture was observed in the wheat inoculated with $R$. irregulare, as indicated by larger root surface area, longer root length, and larger total root volume. Particularly, the $R$. irregulare -inoculated wheat had a significantly larger root surface area in comparison with the non-inoculated controls and thus provided larger contact areas with the soil matrix, allowing the plants to absorb mineral nutrients and water more efficiently, an absolute advantage in stress conditions. Similarly, roots with larger total root volume and longer root length were also of great value in terms of nutrient absorption, by exposing roots to a larger area of soil matrix and by drilling deeper into the soil for more available nutrition (Jones et al., 1989). The enhanced uptake of nutrients, especially phosphorus ions, played a crucial role in the promotion of root development and contributed to the increased root fresh weight and root dry weight in this study. Therefore, it is reasonable to conclude that colonization by the mycorrhizal fungus $R$. irregulare significantly optimized root architecture, which was the structural foundation for increased nutrient uptake capacity, and that the increased water and mineral absorption contributed to heavier root biomass. However, the performance of other AMF strains was not as stable and positive as that of $R$. irregulare.

A comparison between the wheat cultivars shows that FL62R1 performed the best in most cases, with significantly heavier root biomass and better optimized root architecture. In contrast, the Snow bird wheat responded the poorest to mycorrhizal colonization. These findings suggest that in terms of better response to mycorrhization and stronger stress tolerance capacity, the wheat cultivar FL62R1 is more suitable than the commercially used Snowbird wheat.

\subsection{Salinity Treatment}

Salinity had significant negative effects on grain yield, root surface area, and root dry weight at the highest experimental salinity level $\left(100 \mathrm{mmolL}^{-1}\right)$. Regarding the other experimental variables, the salinity levels used in 
this study were too low to induce a detectable stress response on wheat cultivars, themoderately salinity-tolerant crop. Previous studies on the salinity tolerance of wheat used a wide range of salt levels, ranging from $0 \mathrm{mM}$ (control) to $200 \mathrm{mM}$ or even higher (Zair et al., 2003; El-Hendawy et al., 2005), and significant negative effects would generally be observed when the concentration of saline solutions were higher than $150 \mathrm{mmolL}^{-1}$. It has been reported that the salinity levels applied to a moderately salinity-tolerant wheat variety ranged from 0 $\mathrm{mmolL}^{-1}$ to $320 \mathrm{mmolL}^{-1}$ and statistically significant changes were found in most variables where salt solutions higher than 120 or $180 \mathrm{mmolL}^{-1}$. Thus it is reasonable to deduce that the $\mathrm{NaCl}$ concentration of 100 $\mathrm{mmolL}^{-1}$ used in our study did not provide sufficient stress for wheat, leading to insignificant effects of salinity on many of the variables. This study still provided useful information about salinity, however. The strongest saline stress used in the study was equal to slight saline condition if we compare the highest salt concentration to the saturation extract (100 $\mathrm{mmolL}^{-1}$, which equals $5.8 \mathrm{gL}^{-1}$, slightly saline soil conditions). We can therefore deduce that these four wheat cultivars are able to grow in slightly saline soil without negative effects (Brouwer $e t$ al., 1985).

\section{Acknowledgements}

The authors thank HaritikaMajithiaand PrabhjotNandha for their support and Dr. Valerie Gravel for her valuable suggestions for the experiments.

\section{References}

Beltrano, J., Ronco, M. G. (2008). Improved tolerance of wheat plants (Triticumaestivum L.) to drought stress and rewatering by the arbuscular mycorrhizal fungus Glomus claroideum: Effect on growth and cell membrane stability. Braz J Plant Physiol, 20, 29-37. https://doi.org/10.1590/S1677-04202008000100004

Brouwer, C., Goffeau, A., \& Heibloem, M. (1985). Irrigation Water Management: Training Manual No.1 Introduction to Irrigation. Food and Agriculture Organization of the United Nations, Rome, Italy.

Colla, G., Rouphael, Y., Cardarelli, M., Tullio, M., Rivera, C. M., \& Rea, E. (2008). Alleviation of salt stress by arbuscular mycorrhizal in zucchini plants grown at low and high phosphorus concentration. BiolFert Soils, 44, 501-509. https://doi.org/10.1007/s00374-007-0232-8

Daei, G., Ardekani, M. R., Rejali, F., Teimuri, S., \& Miransari, M. (2009). Alleviation of salinity stress onwheat yield, yield components, and nutrient uptake using arbuscular mycorrhizal fungi under field conditions.J Plant Physiol, 166, 617-625. https://doi.org/10.1016/j.jplph.2008.09.013

El-Hendawy, S. E., Hu, Y., Yakout, G. M., Awad, A. M., Hafiz, S. E., \& Schmidhalter, U. (2005). Evaluating salt tolerance of wheat genotypes using multiple parameters. Eur JAgron, 22, 243-253. https://doi.org/10.1016/j.eja.2004.03.002

Evelin, H., Kapoor, R., \& Giri, B. (2009). Arbuscular mycorrhizal fungi in alleviation of salt stress: A review. Ann Bot, 104, 1263-1280. https://doi.org/10.1093/aob/mcp251

Food and Agriculture Organization of the United Nations. (2015). FAOSTATdatabase.Available online at http://faostat3.fao.org/home/E (verified in June 2015).

Gong, M., Tang, M., Chen, H., Zhang, Q., \& Feng, X. (2013). Effects of two Glomus species on the growthand physiological performance of Sophoradavidii seedlings under water stress. New Forests, 44, 399-408. https://doi.org/10.1007/s11056-012-9349-1

Gupta, P. K., Mir RR, Mohan, A., \& Kumar, J. (2008). Wheat genomics: Present status and future prospects. Int J Plant Genomics, 896451. https://doi.org/10.1155/2008/896451

Günal, H., Korucu, T., Birkas, M., Özgöz, E., \& Halbac-Cotoara-Zamfir, R. (2015). Threats to Sustainability of Soil Functions in Central and Southeast Europe. Sustainability, 7, 2161-2188. https://doi.org/10.3390/su7022161

Harley, J. L., Smith, S. E. (1997). Mycorrhizal symbiosis. Mycorrhizal Symbiosis, 3(3), 273-281.

Iman, A., Wahab, Z., Halim, M. R. A., \& Rastan, S. O. S. (2006). The influence of N-P-K fertilizer rates and cropping systems on root biomass and some root morphological variables of sweet corn and vegetable soybean. JAgron, 5, 111-117. https://doi.org/10.3923/ja.2006.111.117

Jones, G. P. D., Blair, G. J., \& Jessop, R. S. (1989). Phosphorus efficiency in wheat—A useful selection criterion? Field Crops Res, 21, 257-264. https://doi.org/10.1016/0378-4290(89)90007-5

Marschner, H., \& Dell, B. (1994). Nutrient uptake in mycorrhizal symbiosis. Plant Soil, 159, 89-102. https://doi.org/10.1007/BF00000098 
Mozafar, A., \& Goodin, J. R. (1986). Salt tolerance of two differently drought-tolerant wheat genotypesduring germination and early seedling growth. Plant Soil, 96, 303-316. https://doi.org/10.1007/BF02375135

Parniske, M. (2008). Arbuscular mycorrhiza: The mother of plant root endosymbioses. Nature RevMicrobiol, 6 , 763-775. https://doi.org/10.1038/nrmicro1987

Pirozynski, K. A., \& Malloch, D. W. (1975). The origin of land plants: a matter of mycotrophism. Biosystems, 6(3), 153-64. https://doi.org/10.1016/0303-2647(75)90023-4

Porcel, R., Aroca, R., \& Ruiz-Lozano, J. M. (2012). Salinity stress alleviation using arbuscular mycorrhizal fungi. A review. Agron Sustain Dev, 32, 181-200. https://doi.org/10.1007/s13593-011-0029-x

Pozo, M. J., Jung, S. C., López-Ráez, J. A., \& Azcón-Aguilar, C. (2010). Impact of arbuscular mycorrhizalsymbiosis on plant response to biotic stress: The role of plant defence mechanisms. InKoltaiH,KapulnikY (eds.) Arbuscular Mycorrhizas: Physiology and Function (2nd Ed). Springer, Dordrecht, Netherlands. pp. 193-207.

Rad, M. Y., Noormohammadi, G., Ardakani, M. R., Hervan, E. M., \& Mirhadi, S. J. (2009). Effect of mycorrhiza on morphological characteristics and nutrients content of barley under different salinity levels. J New Agr Sci, 5, 105-114.

Remy, W., Taylor, T. N., Hass, H., \& Kerp, H. (1994). Four hundred-million-year-old vesiculararbuscular mycorrhizae. P NatlAcadSci USA, 91, 11841-11843. https://doi.org/10.1073/pnas.91.25.11841

Sheng, M., Tang, M., Chen, H., Yang, B., Zhang, F., \& Huang, Y. (2008). Influence of arbuscular mycorrhizae on photosynthesis and water status of maize plants under salt stress. Mycorrhiza, 18, 287-296. https://doi.org/10.1007/s00572-008-0180-7

Sun, S-Z., Guo, Y-Z., Guan, H-L., Hong, L-F., \& Yang, P-C. (2010). Soil salinization characteristics ofcarnationcultivation under different management models and induced diseases. Soils.(in Chinese), 42, 972-977.

Talaat, N. B., \& Shawky, B. T. (2013). Modulation of nutrient acquisition and polyamine pool in salt-stressed wheat (Triticumaestivum L.) plants inoculated with arbuscular mycorrhizal fungi. Acta Physiol Plant, 35, 2601-2610. https://doi.org/10.1007/s11738-013-1295-9

Talaat, N. B., \& Shawky, B. T. (2014). Protective effects of arbuscular mycorrhizal fungi on wheat (Triticumaestivum L.) plants exposed to salinity. Environ Exp Bot, 98, 20-31. https://doi.org/10.1016/j.envexpbot.2013.10.005

Wang, B., \& Qiu, Y-L. (2006). Phylogenetic distribution and evolution of mycorrhizas in land plants.Mycorrhiza, 16, 299-363. https://doi.org/10.1007/s00572-005-0033-6

Zair, I., Chlyah, A., Sabounji, K.,Tittahsen, M., \& Chlyah, H. (2003). Salt tolerance improvement in some wheat cultivars after application of in vitro selection pressure. Plant CellTiss Org Culture, 73, 237-244. https://doi.org/10.1023/A:1023014328638

Zou, Y-N., \& Wu, Q-S. (2011). Efficiencies of five arbuscular mycorrhizal fungi in alleviating salt stressoftrifoliate orange. IntJAgr Biol., 13, 991-995.

\section{Copyrights}

Copyright for this article is retained by the author(s), with first publication rights granted to the journal.

This is an open-access article distributed under the terms and conditions of the Creative Commons Attribution license (http://creativecommons.org/licenses/by/3.0/). 